\title{
Biochemical predictors in presentations to the emergency department after a suicide attempt
}

\author{
Yagci $\mathrm{I}^{1}$, Avci $\mathrm{S}^{2}$ \\ Department of Psychiatry, Kars Harakani State Hospital, Kars, Turkey. ibrahimyagci53@hotmail.com
}

\begin{abstract}
OBJECTIVE: This study was conducted with an aim to determine whether biochemical parameters could be used to identify the individuals at risk of suicide.

METHODS: The experimental group consisted of a total of 46 patients that presented to the emergency department after a suicide attempt. 45 healthy individuals constituted the control group. All subjects were evaluated by using the Beck Depression Inventory (BDI), the Beck Anxiety Inventory (BAI), and the Beck Scale for Suicidal Ideation (BSSI). All subjects were evaluated for leukocyte count, mean platelet volume (MPV), C-reactive protein (CRP), cholesterol, triglyceride levels and neutrophil-lymphocyte ratio (NLR). The Vitamin $D$ levels of the subjects in the experimental group were also measured.

RESULTS: The BAI $(p<0.01)$, BDI $(p<0.01)$, and BSSI $(p<0.01)$ scores of the two groups were significantly different. The two groups were also significantly different in terms of CRP $(p<0.01)$, cholesterol $(p<0.05)$, NLR $(p<0.01)$, MPV $(p<0.01)$, triglyceride $(p<0.01)$ and leukocyte $(p<0.01)$ results. The vitamin $D$ levels of the experimental group were found to be below normal vitamin D levels. High CRP levels were found to be a predictor of anxiety symptoms, and MPV and triglyceride levels were found to be predictors of depressive symptoms.

CONCLUSION: We believe that biochemical parameters can be used to identify people with increased suicide risk, and suicide rates can be reduced by ensuring that these patients receive mental health care in the early period (Tab. 5, Ref. 42). Text in PDF www.elis.sk KEY WORDS: suicide, emergency departments, attempted suicide, risk, psychosocial, biochemical marker.
\end{abstract}

\section{Introduction}

A suicide attempt is an act of self-harm that carries the purpose of ending one's life. Approximately one million people die of suicide globally every year. In addition, suicide ranks 8 th among leading causes of death in population aged 15-44 years (1). All this indicates the significance of suicide as a global public health problem.

Suicide attempts may occur due to psychiatric disorders, psychosocial events, and neurobiological factors (2). It is reported that individuals commonly experience problems in their family and private lives and failures in work or school right before suicide attempts (3). Impulsive behaviors are actions that are taken momentarily without reflecting on possible negative outcomes. The majority of suicide attempts result from impulsive behavior (4). This is why it is important to identify such individuals and to anticipate any possible attempts at taking their own lives.

Although there are significant improvements in the pharmacological treatment of psychiatric disorders, the frequency of sui-

${ }^{1}$ Department of Psychiatry, Kars Harakani State Hospital, Kars, Turkey, and ${ }^{2}$ Department of Emergency Medicine, Amasya University School of Medicine, Amasya, Turkey

Address for correspondence: I. Yagci, MD, Kars Harakani State Hospital, Department of Psychiatry 36000, Kars, Turkey.

Phone: +905322445679 cide and suicide attempts is increasing, and the basic biological mechanisms involved in suicidal behavior are still not clearly understood. A history of suicide attempts is one of the major risk factors for suicidal behavior (5). Impulsive and aggressive personality traits, a feeling of hopelessness, genetic traits, and neurobiological mechanisms are also thought to play a role in suicidal behavior (6).

Efforts to lower serum cholesterol with diet, medication, or a combination of both have been reported to result in an increased number of deaths by suicide. Subsequent studies reported a causal relationship between low serum cholesterol and an increased risk of suicide and violent death (7). There is also a growing body of evidence that suggests a link between inflammation and the pathophysiology of suicide. Studies have shown that patients with immune diseases such as allergies and asthma and patients that undergo cytokine treatment have increased suicidal tendencies and that patients with suicidal behaviors have increased levels of inflammatory markers such as C-reactive protein (CRP), TNF- $\alpha$ and IL-6 in their cerebrospinal fluid and plasma (8). The neutrophillymphocyte ratio (NLR) indicates chronic low-grade inflammation and is used as a predictor of clinical prognosis in neuroimmune diseases. In this regard, authors argue NLR to have better clinical utility than other commonly used parameters such as other leukocyte parameters and IL-6, TNF-alpha and CRP (9).

This study aimed to compare the depressive and anxiety symptoms, the extent of suicidal ideation, and certain biochemical 
parameters [NLR, CRP, cholesterol, triglycerides, mean platelet volume (MPV), and leukocyte count] of the patients that attempted suicide with healthy controls. It also aimed to determine the vitamin D levels of the experimental group. The most important tool in determining suicidal thoughts is psychiatric examination. However, the available psychiatric assessment tools are considered not to be entirely effective. Therefore, recent studies have focused on biological parameters. We hypothesize that biochemical parameters can be used to identify people with increased suicide risk. We did not find a study in which peripheral inflammation markers and vitamin D levels of suicidal individuals were assessed together and believe that our research will contribute to the literature.

\section{Method}

\section{Type of the research}

This study is a case-control type clinical observation study. For the study, ethical approval was obtained from the Ethics Committee of Kafkas University Faculty of Medicine.

\section{Place and time of the research}

This study was conducted between 01/01/2018 and 01/01/2019 at the Amasya Sabuncuoglu Serefeddin Training and Research Hospital Emergency Department.

\section{Universe of the research}

In the calculations, it was determined that for $\alpha=0.05, \beta=$ 0.8 , and an effect size of 0.98 , both experimental and control groups needed to be composed of at least 44 individuals. The experimental group consisted of 46 patients that presented to the Amasya Sabuncuoglu Serefeddin Training and Research Hospital Emergency Department following failed suicide attempts and the control group consisted of 45 healthy individuals without any known chronic diseases.

\section{Inclusion and exclusion criteria}

Inclusion criteria: The criteria for being included in the experimental group were as follows: (a) being admitted to the emergency department for a failed suicide attempt, (b) being aged $\geq 18$ years, and (c) volunteering to participate in the study after being informed. The criteria for being included in the control group were as follows: (a) not having a history of a suicide attempt, (b) not having chronic psychiatric, neurological, cardiovascular, hepatic, renal, hematologic, cardiovascular, or endocrine disease diagnoses in their anamnesis or medical examination, and (c) volunteering to participate in the study after being informed.

Exclusion criteria: For both groups, the exclusion criteria were as follows: (a) not volunteering to participate in the study after being informed, (b) having mental retardation or dementia, (c) substance abuse, and (d) illiteracy. In addition, individuals with a history of infection or allergic reaction one month prior to the evaluation, those using drugs that affect immune or endocrine functions and lipid levels, and patients with malignancy, acute infection, and chronic inflammatory and hematopoietic diseases were excluded from the study.

\section{Assessment tools}

Sociodemographic data form: This form was prepared by the researchers and consists of questions about age, sex, marital status, working status, education status, history of psychiatric illness, and smoking, alcohol, and substance use.

Beck depression inventory (BDI) is a self-report inventory that was developed by Beck et al in 1961 and is used to measure the emotional, somatic, cognitive, and motivational symptoms of depression (10). The validity and reliability of the Turkish version were tested by Hisli et al in 1988 (11).

Beck anxiety inventory (BAI) is a self-report inventory that is used to measure common anxiety symptoms that the individual recently had (12). A higher score indicates more severe anxiety. The validity and reliability of the Turkish version have been tested (13).

Beck scale for suicidal ideation (BSSI) was developed by Beck et al in 1979 to determine and measure the extent of the suicidal thoughts of an individual (14). The validity and reliability of the Turkish version of the scale were assessed by Ozcelik et al (15).

\section{Biochemical parameters}

Blood samples were obtained for analysis from both subject groups after 8-12 hours of fasting. For the experimental group, the blood samples were retrieved on the morning of the day they would be discharged. The retrieved samples were analyzed for vitamin D, triglyceride, cholesterol, NLR, MPV, CRP, and leukocyte counts. The obtained neutrophil and lymphocyte counts were used to calculate the NLR. The vitamin D levels of the controls could not be evaluated; hence, this parameter was evaluated only for the experimental group. Blood samples were retrieved through vascular access by using intravenous cannula. For all blood samples, the serum was separated, placed in Eppendorf tubes and stored at $-80{ }^{\circ} \mathrm{C}$ until analysis.

\section{Statistical analysis}

The data were analyzed by using SPSS (Statistical Package for Social Sciences) for Windows version 16.0. The compatibility of the data with normal distribution was evaluated by the Kolmogorov-Smirnov test. The data were analyzed by using descriptive statistics (mean, standard deviation, number and percentage). In addition, Student's t-test was used for the pairwise comparisons of quantitative parameters with a normal distribution. The chi-square test was used to compare qualitative data. Pearson correlation analysis was used to investigate any relationship between quantitative data. Multiple linear regression analysis was used to determine the effect size of correlated variables. Results were evaluated at $\mathrm{p}<0.05$ with a confidence interval of $95 \%$.

\section{Results}

A total of 91 subjects were included in the study: 46 patients and 45 healthy controls. 57 subjects $(62.6 \%)$ were female and $34(37.4 \%)$ were male. The mean age of the subjects was 32.53 \pm 10.39 years (19-60). The statistical analysis of the sociodemographic data revealed that while the two groups were similar in 
Tab. 1. Sociodemographic characteristics of experimental and control groups.

\begin{tabular}{llccc}
\hline & & $\begin{array}{c}\text { Control } \\
\mathrm{n}(\%)\end{array}$ & $\begin{array}{c}\text { Patient } \\
\mathrm{n}(\%)\end{array}$ & $\mathrm{p}$ \\
\hline Gender & Female & $24(53.3)$ & $33(71.7)$ & \multirow{2}{*}{0.085} \\
& Male & $21(46.7)$ & $13(28.3)$ & \\
\hline Employment & Yes & $38(84.4)$ & $18(39.1)$ & \multirow{2}{*}{$0.000^{* *}$} \\
& No & $7(15.6)$ & $28(60.9)$ & \\
\hline Marital Status & Married & $20(44.4)$ & $23(50)$ & \multirow{2}{*}{0.676} \\
& Single & $25(55.6)$ & $23(50)$ & \\
\hline Educational Status & Elementary & $4(8.9)$ & $19(41.3)$ & \\
& Middle & $2(4.5)$ & $15(32.6)$ & \multirow{2}{*}{$0.000^{* *}$} \\
& High & $20(44.4)$ & $7(15.2)$ & \\
& University & $19(42.2)$ & $5(10.9)$ & \\
\hline $\mathrm{p}<0.05^{*}, \mathrm{p}<0.01^{* *}$ & & & &
\end{tabular}

$\mathrm{p}<0.05^{*}, \mathrm{p}<0.01 * *$

Tab. 2. Independent sample t-test results for the comparison of BDI, BAI, BSSI scores of the two groups.

\begin{tabular}{lllcccc}
\hline & Group & $\mathrm{n}$ & Mean \pm SD & $\mathrm{t}$ & $\mathrm{SD}$ & $\mathrm{p}$ \\
\hline BAI & Patient & 46 & $\begin{array}{c}14.87 \pm 9.94 \\
4.20 \pm 2.22\end{array}$ & -7.028 & 89 & 0.000 \\
& Control & 45 & & & \\
\hline BDI & Patient & 46 & $\begin{array}{c}21.37 \pm 13.07 \\
1.69 \pm 2.30\end{array}$ & -9.949 & 89 & 0.000 \\
& Control & 45 & & & \\
\hline BSSI & Patient & 46 & $12.35 \pm 7.27$ & -4.348 & 89 & 0.000 \\
& Control & 45 & $7.07 \pm 3.72$ & & & \\
\hline
\end{tabular}

$\mathrm{p}<0.05, \mathrm{p}<0.01$, SD: Standard deviation, BDI: Beck Depression Inventory, BAI: Beck Anxiety Inventory, BSSI: Beck Scale for Suicidal Ideation

Tab. 3. Independent sample t-test results for the comparison of triglyceride, cholesterol, leukocyte, neutrophil-lymphocyte ratio, MPV and CRP measurements of the two groups.

\begin{tabular}{|c|c|c|c|c|c|c|}
\hline & Group & $\mathrm{n}$ & Mean \pm SD & $\mathrm{t}$ & $\mathrm{SD}$ & $\mathrm{p}$ \\
\hline Leukocyte $\left(10^{3} / \mathrm{ul}\right)$ & $\begin{array}{l}\text { Patient } \\
\text { Control }\end{array}$ & $\begin{array}{l}46 \\
43\end{array}$ & $\begin{array}{l}9415.65 \pm 3952.25 \\
7070.23 \pm 1880.59\end{array}$ & -4.435 & 87 & 0.000 \\
\hline MPV (fL) & $\begin{array}{l}\text { Patient } \\
\text { Control }\end{array}$ & $\begin{array}{l}46 \\
38 \\
\end{array}$ & $\begin{array}{c}10.36 \pm 0.90 \\
8.55 \pm 1.25 \\
\end{array}$ & -7.704 & 82 & 0.000 \\
\hline NLR & $\begin{array}{l}\text { Patient } \\
\text { Control }\end{array}$ & $\begin{array}{l}46 \\
39 \\
\end{array}$ & $\begin{array}{c}2.77 \pm 1.6 \\
2.05 \pm 0.59 \\
\end{array}$ & -2.672 & 83 & 0.009 \\
\hline CRP (mg/L) & $\begin{array}{l}\text { Patient } \\
\text { Control }\end{array}$ & $\begin{array}{l}27 \\
41 \\
\end{array}$ & $\begin{array}{l}3.36 \pm 4.75 \\
0.17 \pm 0.20 \\
\end{array}$ & -4.305 & 66 & 0.000 \\
\hline Cholesterol (mg/dl) & $\begin{array}{l}\text { Patient } \\
\text { Control }\end{array}$ & $\begin{array}{l}43 \\
45 \\
\end{array}$ & $\begin{array}{l}157.16 \pm 36.05 \\
174.71 \pm 35.32 \\
\end{array}$ & 2.306 & 86 & 0.023 \\
\hline Triglycerides (mg/dl) & $\begin{array}{l}\text { Patient } \\
\text { Control }\end{array}$ & $\begin{array}{l}41 \\
42 \\
\end{array}$ & $\begin{array}{c}85.32 \pm 50.74 \\
133.19 \pm 65.85 \\
\end{array}$ & 3.704 & 81 & 0.000 \\
\hline Vitamin D (ng/ml) & Patient & 31 & $13.25 \pm 8.10$ & & & \\
\hline
\end{tabular}

$\mathrm{p}<0.05, \mathrm{p}<0.01$, SD: Standard deviation, MPV: Mean Platelet Volume, NLR: Neutrophil/lymphocyte Ratio, CRP: C-reactive protein

Tab. 4. Examination of the relationship between BDI, BAI and BSSI scores and certain measurements of the participants.

\begin{tabular}{|c|c|c|c|c|c|c|}
\hline & \multicolumn{2}{|c|}{ BAI } & \multicolumn{2}{|c|}{ BDI } & \multicolumn{2}{|c|}{ BSSI } \\
\hline & $\mathrm{r}$ & $\mathrm{p}$ & $\mathrm{r}$ & $\mathrm{p}$ & $\mathrm{r}$ & $\mathrm{p}$ \\
\hline Triglycerides (mg/dl) & -0.180 & 0.103 & -0.305 & 0.005 & -0.042 & 0.709 \\
\hline MPV (fL) & 0.410 & 0.000 & 0.467 & 0.000 & 0.100 & 0.363 \\
\hline NLR & -0.12 & 0.916 & -0.034 & 0.754 & 0.067 & 0.540 \\
\hline $\mathrm{CRP}(\mathrm{mg} / \mathrm{L})$ & 0.583 & 0.000 & 0.409 & 0.000 & 0.311 & 0.01 \\
\hline Cholesterol (mg/dl) & -0.134 & 0.213 & -0.182 & 0.089 & -0.009 & 0.932 \\
\hline Leukocyte $\left(10^{3} / \mathrm{ul}\right)$ & 0.197 & 0.064 & 0.207 & 0.052 & 0.195 & 0.066 \\
\hline
\end{tabular}

$\mathrm{p}<0.05, \mathrm{p}<0.01$, BDI: Beck Depression Inventory, BAI: Beck Anxiety Inventory, BSSI: Beck Scale for Suicidal Ideation, MPV: Mean Platelet Volume, NLR: Neutrophil/lymphocyte ratio, CRP: C-reactive protein terms of age, sex and marital status, there was a significant difgroups (Tab. 1).

The BAI $(\mathrm{p}<0.01)$, BDI $(\mathrm{p}<0.01)$ and BSSI $(\mathrm{p}<0.01)$ min D levels of the experimental group were found to be

We have investigated any correlation between biochemical parameters and scale scores. There was a positive moderate correlation between BAI scores and MPV values. There was a positive moderate correlation between BDI scores and MPV values. There was a negative weak correlation between BDI scores and cholesterol and triglycerides levels and BDI, BAI and seres; however, this correlation was not statistically siglevels and BDI, BAI, BSSI scores; however, this correlation was not statistically significant (Tab. 4).

Multiple linear regression analysis was performed to determine whether MPV, CRP and triglyceride levels are associated with BAI, BDI and BSSI scores. MPV levels were found to impact depression scores $\left[\mathrm{F}_{(3.80)}=7.603 ; \mathrm{p}<0.01\right]$. MPV results affect $22.2 \%$ of depression scores. In other words, MPV levels can explain $22.2 \%$ of all cases of depression. CRP levels were found to impact anxiety scores $\left[_{\mathrm{F}(3.64)}=11.716\right.$; $\mathrm{p}<0.01]$. CRP results affect $35.5 \%$ of anxiety scores. In other words, CRP levels can explain $35.5 \%$ of all cases of anxiety. Triglycerides levels were found to impact depression scores $\left[\mathrm{F}_{(3.11)}=8.331 ; \mathrm{p}<0.01\right]$. Triglyceride results affect $0.09 \%$ of depression scores. In other words, triglyceride levels can explain $0.09 \%$ of all cases of depression (Tab. 5).

\section{Discussion}

Our results indicate that the experimental and control groups were not different in terms of age, gender or marital status. However, the average education level of the experimental group was found to be lower than that of the control group. Furthermore, the unemployment rate was significantly higher in the experimental group. Educa- 
Tab. 5. Multiple linear regression analysis regarding whether MPV, CRP and triglyceride measurements affect beck anxiety, depression and suicidal ideation scores.

\begin{tabular}{|c|c|c|c|c|c|c|}
\hline & & B & $\begin{array}{l}\text { Standart } \\
\text { Error B }\end{array}$ & B & $\mathrm{T}$ & $\mathrm{p}$ \\
\hline \multirow[t]{4}{*}{$\overline{\mathrm{MPV} \text { (fL) }}$} & Constant & 8.921 & 0.273 & & 32.666 & 0.000 \\
\hline & BAI & 0.015 & 0.026 & 0.098 & 0.581 & 0.563 \\
\hline & BDI & 0.040 & 0.017 & 0.392 & 2.342 & $0.022 *$ \\
\hline & BSSI & -0.003 & 0.022 & -0.014 & -0.140 & 0.88 \\
\hline $\mathrm{R}=0.471$ & $\mathrm{R}^{2}=0.222$ & \multicolumn{3}{|c|}{$F_{(3.80)}=7.603$} & \multicolumn{2}{|c|}{$\mathrm{p}=0.000^{* *}$} \\
\hline \multirow[t]{4}{*}{$\overline{\mathrm{CRP}}(\mathrm{mg} / \mathrm{L})$} & Constant & -1.123 & 0.664 & & -1.692 & 0.095 \\
\hline & BAI & 0.285 & 0.071 & 0.661 & 3.989 & 0.000 \\
\hline & BDI & -0.039 & 0.043 & -0.150 & -0.911 & 0.365 \\
\hline & BSSI & 0.056 & 0.066 & 0.096 & 0.861 & 0.392 \\
\hline $\mathrm{R}=0.595$ & $\mathrm{R}^{2}=0.355$ & \multicolumn{3}{|c|}{$\mathrm{F}_{(3.64)}=11.716$} & \multicolumn{2}{|c|}{$\mathrm{p}=0.000^{*} *$} \\
\hline \multirow{2}{*}{\multicolumn{2}{|c|}{$\begin{array}{r}\text { Triglycerides }(\mathrm{mg} / \mathrm{dl}) \text { Const } \\
\text { BDI }\end{array}$}} & 125.547 & 8.661 & & 14.495 & 0.000 \\
\hline & & -1.418 & 0.491 & -0.305 & -2.886 & $0.005 * *$ \\
\hline
\end{tabular}

$\mathrm{p}<0.05^{*}, \mathrm{p}<0.01^{* *}$, BDI: Beck Depression Inventory, BAI: Beck Anxiety Inventory, BSSI: Beck Scale for Suicidal Ideation, MPV: Mean Platelet Volume, CRP: C-reactive protein

tion level is one of the most important socioeconomic indicators. Several publications have reported that suicide and unemployment are correlated and hence, suicides are more common in lower socioeconomic levels. In this study, the number of women in the experimental group was significantly higher than men. The characteristically low female labor force participation rate and education level in Turkey may be the reason behind the differences in education levels and working statuses of the two groups.

Women more commonly attempt suicide, but men more commonly complete suicide attempts (16). Among the reasons for this difference is that men are more active, and women are more passive in nature. Another reason may be the differences in the help-seeking behavior of men and women. In our study, we only included individuals that attempted but did not complete suicide and found that our subjects were predominantly women. Men often prefer methods like using firearms, hanging and jumping from a height, whereas women commonly prefer drug overdose, poison, and wrist-cutting (16). In our study, the most common suicide method was drug overdose, followed by hanging, chemical poisoning and cutting. The reason behind the unusual prevalence of these suicide methods may be associated with the fact that we only included individuals that attempted suicide but have failed.

The most important risk factor for suicide is the presence of a psychiatric disorder. More than $90 \%$ of individuals that attempt suicide have psychiatric disorders (17). Patients diagnosed with major depression, alcohol abuse, bipolar disorder, schizophrenia, antisocial personality disorder and anxiety disorder have an increased risk of suicide (17). The short-term predictors of suicide attempts are anhedonia, anxiety and alcohol abuse, while the long-term predictors are mood fluctuations and feelings of despair (18). Our subjects did not undergo psychiatric assessment. However, compared to healthy controls, subjects that attempted suicide scored significantly higher on Beck Depression, Anxiety and Suicidal Ideation selfreporting inventories. This result is consistent with the literature.

In our study, CRP levels were statistically significantly higher in individuals who attempted suicide than in the control group. In addition, there was a statistically significant positive correlation between CRP levels and BDI, BAI and BSSI scores. The literature indicates that inflammation is associated with the pathophysiology of suicide attempts. However, the causal relationship is still not clear $(19,20)$. Individuals that attempted suicide were determined to have increased cytokines, acute-phase proteins and peripheral inflammatory indicators such as lymphocyte cell activation (20). In contrast, several publications argue that suicide attempts are not associated with inflammatory processes but with major depression (21). In addition, high CRP levels are a predictor of the severity of anxiety symptoms. Therefore, parameters showing inflammatory changes in individuals can be used to identify people at risk before a suicide attempt.

Neutrophil-lymphocyte ratio (NLR) is obtained by dividing the neutrophil count by the lymphocyte count and is a peripheral inflammatory indicator that designates chronic low-grade inflammation (9). It is more reliable than other leukocyte parameters and commonly used markers such as IL-6, TNF- $\alpha$ and CRP $(9,22)$. It was reported that the NLR value of individuals that attempted suicide was higher than in those with major depression, but this difference was not statistically significant (23). Another study found that the NLR value had increased in patients with bipolar disorder (BD) that attempted suicide and that the NLR value of BD patients who did not attempt suicide was similar to healthy controls (24). In our study, the NLR values of the experimental group were significantly higher than those of the control group. Also, there was a positive correlation between NLR levels and BDI, BAI and BSSI scores; however, this correlation was not statistically significant. Based on this data, we believe that increased NLR can be used as a predictor of suicidal behavior.

Authors argue that decreased cholesterol levels are associated with impulsive behavior, aggression, violent behavior and suicide attempts (25). This phenomenon has been explained by the decreased fluidity of neuronal membranes that result from reduced cholesterol levels, which translates into reduced serotonin receptor sensitivity and decreased pre- and postsynaptic 5-HT neurotransmission. This reduced central serotonin activity is associated with aggression and suicidal behavior $(26,27)$. Decreased serotonin (5-HT) activity is known to be linked to both aggressive and suicidal behavior $(26,27)$. Multiple studies demonstrated decreased cholesterol levels in suicidal individuals compared to controls (28-30). Contrarily, Apter et al associated aggression, impulsivity, and suicidal behavior with high cholesterol levels in adolescents (31). There exist conflicting findings in the literature. In our study, cholesterol and triglyceride levels were found to be significantly reduced. In addition, there was a negative correlation between cholesterol and triglyceride levels and Beck Depression, Anxiety, Suicidal Ideation scores; however, this correlation was not statistically significant. Triglycerides are a predictor of depressive symptoms. 
In our study, MPV values were significantly higher in the experimental group, consistent with the literature. Furthermore, there was a statistically significant positive correlation between MPV levels and BDI and BAI scores. Platelets in the plasma can synthesize, release, and retrieve serotonin. Moreover, selective serotonin reuptake inhibitor treatment can decrease platelet activity. Peripheral platelet models are widely used as indicators of central serotonin (5-HT) metabolism because they reflect central serotonergic function (32). Serotonin, a neurotransmitter in the central nervous system, plays an important role in regulating vascular tone and the regulation of platelet aggregation in the vascular system (33). MPV is considered an indicator of platelet activity. Platelets contain serotonin (5-HT) receptors on their membranes, such as 5-HT2A, 5-HT3 and 5-HT transporter (5-HTT) (33). Canan et al reported that MPV values had increased in people diagnosed with major depression but decreased after 8 weeks of escitalopram therapy (34). Several studies indicated a positive correlation between platelet 5-HT2A receptor density and the suicidal behavior item of the Hamilton Depression Scale or impulsivity in a suicide attempt $(35,36)$. Our results are consistent with the literature. We found that high MPV levels are a predictor of the severity of depressive symptoms. Since the severity of depressive symptoms is known to be associated with suicide risk, it can be said that high MPV levels are an important parameter in predicting suicide risk.

Low vitamin D levels are also associated with different psychiatric disorders. Vitamin D is considered to be deficient at levels below $20 \mathrm{ng} / \mathrm{mL}$ (37). In our study, the mean vitamin D level in the experimental group was $13.25 \pm 8.10 \mathrm{ng} / \mathrm{mL}$ and the vitamin D level of only 6 subjects was above $20 \mathrm{ng} / \mathrm{mL}$. Two recent prospective studies have found that low vitamin D levels increase the risk of depression $(38,39)$. It has also been shown that one year of vitamin D supplementation has beneficial effects on depressive symptoms in obese patients (40). Multiple articles have reported an association between vitamin D deficiency and an increased risk of suicide (41). There are 2 different theories regarding the contribution of vitamin D deficiency to suicidal tendencies. The first of these is its effect on serotonin levels. The active form of vitamin $\mathrm{D}$ has been shown to activate the transcription of tryptophan hydroxylase 2 (TPH2), the gene that synthesizes serotonin in the brain. The active form of vitamin D has been shown to increase p11 (also known as S100A10), a protein that interacts with the 5-hydroxytryptamine (5-HT) $1 \mathrm{~B}$ receptor (serotonin receptor) and is transported from the cytoplasm to the membrane (42). Low serotonin levels have been associated with characteristic behaviors of suicidal patients, for instance aggressive suicide attempts and impulsive behavior. The second theory is that vitamin D increases the levels of anti-inflammatory cytokines such as IL-10, IL-4, IL-5 and transforming growth factor (TGF)- $\beta$ and reduces pro-inflammatory cytokines (37). Vitamin D deficiency is associated with elevated pro-inflammatory cytokines, as vitamin D modulates and prevents uncontrolled systemic and CNS inflammation. Based on these data, it can be inferred that vitamin D deficiency may be a marker of suicidal behavior.

Our study has several limitations. The first limitation is the single-center nature of the study. The second limitation is that the subjects did not undergo psychiatric evaluation and that they were only evaluated using self-reporting psychiatric assessment scales. Therefore, we do not know whether or not subjects that attempted suicide have comorbid psychiatric disorders. The third limitation is that the pre-suicide attempt laboratory examinations are not available and could not be compared to the available results. We believe prospective studies will help provide more definitive conclusions. Another limitation is the small number of subjects in both experimental and control groups. However, this limitation may not be significant since the required sample size for $\alpha=$ $0.05, \beta=0.8$, and an effect size of 0.98 was 44 subjects each in experimental and control groups, and our experimental and control groups had 46 and 45 subjects, respectively. More conclusive data can be obtained with studies with larger samples.

\section{Conclusions}

We evaluated certain psychosocial characteristics and biochemical parameters that we believed may be associated with the etiology of suicide attempts. In our study, anxiety, depression, and suicidal ideation scores were higher in the experimental group. Also, CRP, MPV, NLR and leukocyte count were significantly higher in the experimental group whereas vitamin D, cholesterol and triglyceride levels were significantly lower. The two groups were similar in sociodemographic characteristics except for educational and working status. Our study may be important because it is the first study to evaluate all biochemical parameters that are thought to be involved in suicide etiology simultaneously. Individuals that attempt suicide are initially brought in to the emergency department of hospitals and the majority of these patients are discharged from emergency departments after treatment. Therefore, it is crucial to determine the gravity of these cases in the emergency department. Individuals commonly refer to the emergency department of the hospitals or family physicians in primary care facilities before attempting suicide. The parameters included in this study can be evaluated in every health care facility. Therefore, if a patient expresses suicidal tendencies, these parameters should be evaluated and patients with abnormal laboratory results should immediately be referred to psychiatric consultation. We believe that this approach can contribute to reducing suicide attempt rates.

\section{References}

1. World Health Organisation. The global burden of disease report: Geneva, Switzerland: WHO, 2008.

2. Ducasse D, Olié E, Guillaume S, Artéro S, Courtet P. A metaanalysis of cytokines in suicidal behavior. Brain Behav Immun 2015; 46: 203-211.

3. Şenol V, Ünalan D, Avşaroğullari D, Ikizceli I. An analysis of patients admitted to the Emergency Department of Erciyes University Medical School due to suicidal attempt. Anadolu Psikiyatri Derg 2005; 6 (1): 19-29.

4. Gould M, Shaffer D, Fisher P, Kleinman M, Morishima A. The clinical prediction of adolescent suicide: In Marris R, Berman A, Maltsberger J, Yufit R (editors). Assessment and prediction of suicide. New York: Guilford Press, 1992, 130-143. 
5. Brundin L, Erhardt S, Bryleva EY, Achtyes ED, Postolache TT. The role of inflammation in suicidal behaviour. Acta Psychiatr Scand 2015; 132 (3): 192-203.

6. Perroud N, Baud P, Mouthon D, Courtet P, Malafosse A. Impulsivity, aggression and suicidal behavior in unipolar and bipolar disorders. J Affect Disord 2011; 134 (1-3): 112-118.

7. Muldoon MF, Manuck SB, Mathews KM. Lowering cholesterol concentrations and mortality: a quantitative review of primary prevention trials. Br Med J 1990; 301 (6747): 309-314.

8. Janelidze S, Mattei D, Westrin Å, Träskman-Bendz L, Brundin L. Cytokine levels in the blood may distinguish suicide attempters from depressed patients. Brain Behav Immun 2011; 25 (2): 335-339.

9. Imtiaz F, Shafique K, Mirza SS, Ayoob Z, Vart P, Rao S. Neutrophil lymphocyte ratio as a measure of systemic inflammation in prevalent chronic diseases in Asian population. Int Arch Med 2012; 5 (1): 2

10. Beck AT. An inventory for measuring depression. Arch Gen Psychiatry 1961; 4: 561-71.

11. Hisli N. Beck Depresyon Envanterinin üniversite öğrencileri için geçerliliği ve güvenirliliği. Psikoloji Dergisi 1989; 7: 3-13.

12. Beck AT, Epstein N, Brown G. An inventory for measuring clinical anxiety: Psychometric properties. J Consult Clin Psychol 1998; 56 (6): 893-897.

13. Ulusoy M, Şahin N, Erkmen H. Turkish version of The Beck Anxiety İnventory: psychometric properties. J Cogn Psychoterapy 1996; 12 (2): $163-172$.

14. Beck AT, Kovacs M, Weissman A. Assessment of suicidal intention: the Scale for Suicide Ideation. J Consult Clin Psychol 1979; 47 (2): 343-352.

15. Özçelik HS, Ozdel K, Bulut SD, Orsel S. The Reliability And Validity Of The Turkish Version Of The Beck Scale For Suicide Ideation (Turkish BSSI). Bulletin Of Clinical Psychopharmacology 2015; 25 (2): 141-150.

16. Özsoy SD, Eşel E. İntihar (Özkiyim). Anadolu Psikiyatri Derg 2003; 4 (3): 151-158.

17. Rich CL, Runeson BS. Similarities in diagnostic comorbidity between suicide among young people in Sweeden and the United States. Acta Psychiatr Scand 1992; 86 (5): 335-339.

18. Fawcett J, Scheftner WA, Fogg L, Clark DC, Young MA, Hedeker D, Gibbons R. Time related predictors of suicide in major affective disorder. Am J Psychiatry 1990; 147 (9): 1189-1194.

19. Janelidze S, Mattei D, Westrin Å, Träskman-Bendz L, Brundin L. Cytokine levels in the blood may distinguish suicide attempters from depressed patients. Brain Behav Immun 2011; 25 (2): 335-339.

20. Serafini G, Pompili M, Elena Seretti M, Stefani H, Palermo M, Coryell W, Girardi P. The role of inflammatory cytokines in suicidal behavior: a systematic review. Eur Neuropsychopharmacol 2013; 23 (12): 1672-1686.

21. Lee KM, Kim YK. The role of IL-12 and TGF-beta1 in the pathophysiology of major depressive disorder. Int Immunopharmacol 2006; 6 (8): 1298-1304.

22. Kalelioglu T, Karamustafalioglu N. "A new interpretation of neutrophil-lymphocyte ratio from psychiatric aspect." Bratislavske lekarske listy 2019; 120 (8): 604 .

23. Meydaneri GG, Meydaneri S. Can neutrophil lymphocyte ratio predict the likelihood of suicide in patients with major depression? Cureus 2018; 10 (4): e2510.

24. Ivković M, Pantović Stefanović M, Dunjić Kostić B, Jurišić V, Lačković M, Totić Poznanović S, Jovanovića AA, Damjanović A. Neutrophil to lymphocyte ratio predicting sui-cide risk in euthymic patients with bipolar disorder: Moderatory effect of family history. Compr Psychiatry 2016; 66: 87-95.
25. Rich CL, Warstradt GM, Nemiroff RA, Fowler RC. Young D, Warsradt GM. Suicide, stressors, and the life cycle. Am J Psychiatry 1991; 148 (4): 524-527.

26. Brown GL, Ebert MH, Goyer PF, Jimerson DC, Klein WJ, Bunney WE, Goodwin FK. Aggression, suicide, and serotonin: Relationships to CSF amine metabolites. Am J Psychiatry 1982, 139 (6): 741-746.

27. Coccaro EF, Siever LJ, Klar HM, Maurer G, Cochrane K, Cooper TB, Mohs RC, Davis KL. Serotonergic studies in patients with affective and personality disorders correlates with suicidal and impulsive-aggressive behavior. Arch Gen Psychiatry 1989, 46 (7): 587-599.

28. Golier JA, Marzuk PM, Leon AC, Weiner C, Tardiff K. Low serum cholesterol and attempted suicide. Am J Psychiatry 1996; 152 (3): 419-423.

29. Lindberg G, Rastam L, Gallberg B, Eklund GA. Low serum cholesterol concentration and short term mortality from injuries in men and women. BMJ 1992; 305: 277-279.

30. Zureik M, Courbon D, Ducimetiere P. Serum cholesterol concentration and death from suicide in men: Paris prospective study I. BMJ 1996; 313: 649-651.

31. Apter A, Laufer N, Bar-Sever M, Har-Even D, Ofek H, Weizman A. Serum cholesterol, suicidal tendencies, impulsivity, aggression, and depression in adolescent psychiatric inpatients. Biol Psychiatry 1999; 46 (4): 532-541.

32. Marazziti D, Rossi A, Dell'Osso L. Decreased platelet 3H-paroxetine binding in untreated panic disorder patients. Life Sci 1999; 65 (25): 27352741.

33. Purselle DC, Nemeroff CB. Serotonin transporter: a potential substrate in the biology of suicide. Neuropsychopharmacology 2003; 28 (4): 613-619.

34. Ataoglu A, Canan F. Mean platelet volume in patients with major depression: effect of escita-lopram treatment. J Clin Psychopharmacol 2009; 29 (4): 368-371.

35. Bakish D, Cavazzoni P, Chudzik J, Ravindran A, Hrdina PD. Effects of selective serotonin reuptake inhibitors on platelet serotonin parameters in major depressive disorder. Biol Psychiatry 1997; 41 (2): 184-190.

36. Rao ML, Hawellek B, Papassotiropoulos A, Deister A, Frahnert C. Upregulation of the platelet Serotonin2A receptor and low blood serotonin in suicidal psychiatric patients. Neuropsychobiology 1998; 38 (2): 84-89.

37. Vitamin D: Fact sheet for health professionals [Fact sheet]. (updated 2020 March 24). Retrieved April 16, 2020, Available from https: //ods.od.nih. gov/factsheets/VitaminD-HealthProfessional/

38. Bertone-Johnson ER. Vitamin $D$ and the occurrence of depression: causal association or circumstantial evidence? Nutr Rev 2009; 67 (8): 481-492.

39. Ganji V, Milone C, Cody MM, McCarty F, Wang YT. Serum vitamin $\mathrm{D}$ concentrations are related to depression in young adult US population: the Third National Health and Nutrition Examination Survey. Int Arch Med 2010; 3 (1): 29.

40. Ersoy N, Gülgün E. "Vitamin D deficiency and Depression: What Can We Do?." Hacettepe Üniversitesi Sağlik Bilimleri Fakültesi Dergisi 2017; 4 (3): 1-14.

41. Baltaci D, Karakiliç O, Kara İH. Depresyon ve intihar girişimi ile vitamin B12 ve kolesterol değerleri arasindaki ilişki. Prusias Tip Dergisi 2016; 1 (1): 28-36.

42. Zhang L, Su TP, Choi K, Maree W, Li CT, Chung MY, Chen YS, Bai YM, Chou YH, Barker JL, Barrett JE, Li XX, Li H, Benedek DM, Ursano R. P11 (S100A10) as a potential biomarker of psychiatric patients at risk of suicide. J Psychiatr Res 2011; 45 (4): 435-441.

Received June 19, 2020. Accepted October 10, 2020. 